OPEN ACCESS

Edited by:

Céline Aguer,

Institut du Savoir Montfort (ISM),

Canada

Reviewed by:

Christoph Handschin,

Biozentrum - Universität Basel,

Switzerland

Chiara Dallaman

University of Padova, Italy

${ }^{*}$ Correspondence:

Jose E. Galgani

jgalgani@uc.cl

Specialty section:

This article was submitted to

Exercise Physiology,

a section of the journal

Frontiers in Physiology

Received: 23 January 2019

Accepted: 24 July 2019

Published: 08 August 2019

Citation:

Mizgier ML, Fernández-Verdejo R

Cherfan J, Pinget M, Bouzakri K and Galgani JE (2019) Insights on the Role of Putative Muscle-Derived Factors on

Pancreatic Beta Cell Function.

Front. Physiol. 10:1024.

doi: 10.3389/fphys.2019.01024

\section{Insights on the Role of Putative Muscle-Derived Factors on Pancreatic Beta Cell Function}

\author{
Maria L. Mizgier ${ }^{1}$, Rodrigo Fernández-Verdejo ${ }^{2}$, Julien Cherfan', Michel Pinget ${ }^{1}$, \\ Karim Bouzakri' and Jose E. Galgani',3* \\ ' UMR DIATHEC, EA 7294, Centre Européen d'Etude du Diabète, Université de Strasbourg, Strasbourg, France, \\ ${ }^{2}$ Departamento de Ciencias de la Salud, Nutrición y Dietética, Facultad de Medicina, Pontificia Universidad Católica \\ de Chile, Santiago, Chile, ${ }^{3}$ Departamento de Nutrición, Diabetes y Metabolismo, Facultad de Medicina, Pontificia \\ Universidad Católica de Chile, Santiago, Chile
}

Skeletal muscle is a main target of insulin action that plays a pivotal role in postprandial glucose disposal. Importantly, skeletal muscle insulin sensitivity relates inversely with pancreatic insulin secretion, which prompted the hypothesis of the existence of a skeletal muscle-pancreas crosstalk mediated through an endocrine factor. The observation that changes in skeletal muscle glucose metabolism are accompanied by altered insulin secretion supports this hypothesis. Meanwhile, a muscle-derived circulating factor affecting in vivo insulin secretion remains elusive. This factor may correspond to peptides/proteins (so called myokines), exosomes and their cargo, and metabolites. We hereby review the most remarkable evidence encouraging the possibility of such inter-organ communication, with special focus on muscle-derived factors that may potentially mediate such skeletal muscle-pancreas crosstalk.

Keywords: myokines, miRNA, exosomes, insulin secretion, insulin sensitivity, muscle, beta cell, crosstalk

\section{INTRODUCTION}

Skeletal muscle is the largest organ in lean humans that plays a main physiological role in insulinstimulated glucose disposal (Baron et al., 1988). To accomplish this, muscle cells adapt their metabolism to changes in circulating metabolites and hormones. Muscle cell adaptation also involves autocrine and paracrine interaction among cell types (Pillon et al., 2013). Thus, several muscle cell-derived factors have been detected, including myokines (Bouzakri et al., 2011; Raschke et al., 2013; Scheler et al., 2013; Hartwig et al., 2014; Mizgier et al., 2017), exosomes and their cargo (Forterre et al., 2014), and metabolites (Daskalaki et al., 2018). Whether or not musclederived factors increase in blood at a sufficient magnitude to influence distant organs has not yet been elucidated.

Among muscle-targeted organs, a crosstalk between skeletal muscle and the pancreas has been proposed (Bouzakri et al., 2011; Mizgier et al., 2017; Rutti et al., 2018). Pancreatic beta cells secrete insulin to facilitate glucose disposal in insulin-sensitive tissues such as skeletal muscle, so hyperand hypo-glycemia are prevented. The extent at which insulin is secreted depends of the amount of glucose taken up by beta cells (Rorsman and Braun, 2013). Furthermore, beta cells receive information from other organs to adjust insulin secretion. For instance, when glycemia is low, the brain increases sympathetic activity to suppress insulin secretion, which raises glycemia back to normal levels (Porte, 1969). 
Whether a similar mechanism is activated under conditions of high glycemia (e.g., after meals) is unknown. Since skeletal muscle is the main tissue responsible for insulin-mediated glucose disposal (Baron et al., 1988), it is intuitive to propose that skeletal muscle can signal back toward the pancreas. Such organ crosstalk may allow adjusting insulin secretion to insulin demands to maintain glycemia within the physiological range. Here, we will discuss the most remarkable evidence supporting such a muscle-pancreas crosstalk, and the progress made in identifying the endocrine mediator.

\section{PHYSIOLOGICAL RELEVANCE OF A PUTATIVE SKELETAL MUSCLE-PANCREAS CROSSTALK}

Pancreatic insulin secretion must tightly match insulin demands for proper glycemic control. Upon glucose ingestion, the increase in glycemia and glucose transport into pancreatic beta cells may suffice to adapt insulin secretion to insulin demand. In turn, higher glycemia often observed in insulin resistance, especially in postprandial conditions (Petersen et al., 2004; Galgani and Ravussin, 2012), may also be sufficient to elevate insulin secretion. Thus, blood glucose concentration might itself be the factor contributing to adjust insulin secretion.

However, convincing evidence shows that blood glucose concentration cannot entirely accommodate insulin secretion to insulin demand (Kahn et al., 1989, 1990). Another physiological mechanism must therefore exist to maintain glycemic control. The skeletal muscle-pancreas crosstalk appears as an attractive hypothesis. The fact that insulin is secreted as an inverse function of insulin sensitivity under fasting and postprandial conditions (Galgani et al., 2014) reinforces the notion of such organ crosstalk (Mizgier et al., 2014). The mechanism underlying this association remains elusive. But, it may be mediated by a factor coming from skeletal muscle (and eventually from other insulin-sensitive tissues). Thus, skeletal muscle may play a pivotal physiological role in the adjustment of insulin secretion to maintain glycemic control throughout the day.

\section{EVIDENCE SUGGESTING A SKELETAL MUSCLE-PANCREAS CROSSTALK}

A large-scale, multi-center study investigated which factors determine the change in insulin secretion (by plasma C-peptide concentration) during an isoglycemic-hyperinsulinemic clamp (Mari et al., 2011). The analysis highlighted insulin-stimulated glucose disposal rate as a direct determinant of insulin secretion. That finding was independent of sex, age, family history of diabetes and body mass index. Noteworthy, that association was attenuated in individuals with altered glycemic control. One can suggest that the extent to which glucose is taken up in skeletal muscle, as a main insulin-sensitive glucose disposal site (Baron et al., 1988), somehow determines pancreatic beta cell function. Alternatively, skeletal muscle insulin sensitivity may just reflect beta cell insulin sensitivity. The observation that insulinemia during the isoglycemic clamp related positively with insulin secretion suggests a direct action of insulin on its secretion (Mari et al., 2011). Pursuing that latter hypothesis, i.e., that insulin enhances its secretion through a direct effect on beta cell function, a sophisticated study was conducted in humans (Halperin et al., 2012).

The study compared the effect of saline vs. insulin infusion on glucose-stimulated insulin secretion (GSIS) in individuals with normal and abnormal glycemic control (Halperin et al., 2012). Blood glucose concentration was maintained at similar values in both sessions by co-infusing glucose throughout the insulin infusion session. When compared with saline, the insulin infusion increased GSIS in healthy individuals. Such effect was attenuated in volunteers with altered glycemic control. These results were interpreted as proof that insulin stimulates its own secretion in pancreatic beta cells. Furthermore, lower GSIS in subjects with altered glycemic control may fit with a state of beta cell insulin resistance. Taken together, these findings were considered in agreement with some in vitro data showing that insulin stimulates its secretion (Aspinwall et al., 1999; Srivastava and Goren, 2003; Jimenez-Feltstrom et al., 2004; Caporarello et al., 2017; Supplementary Table 1).

However, other studies have not confirmed that insulin (in vitro) stimulates its secretion (reviewed in Leibiger et al., 2008 and updated in Supplementary Table 1). For instance, a neutral effect was reported in isolated rat islets (Zawalich and Zawalich, 2002) and a rat beta cell line (INS-1) (Collier et al., 2004). Even more, an inhibitory action was concluded from experiments in perfused canine pancreases (Iversen and Miles, 1971); human islets (Johnson and Misler, 2002; Persaud et al., 2002); rat islets (Araujo et al., 2002); mouse beta cells; and INS1 cells (Collier et al., 2004). Unpublished findings from our group also support an inhibitory action. Briefly, isolated mouse islets in which insulin signaling was inhibited (with wortmannin) displayed higher GSIS. This suggests that insulin secreted upon glucose stimulation decreased further insulin secretion.

Aforementioned findings in vitro are controversial (Supplementary Table 1), although it predominates an inhibitory action of insulin on its secretion. A study that assessed C-peptide release at different insulin concentrations in mouse islets might enlighten an answer. This study showed that insulin stimulated its secretion when tested at concentrations between 0.05 to $0.1 \mathrm{nM}$. In turn, insulin inhibited its secretion at a higher concentration ( $1 \mu \mathrm{M})$ (Jimenez-Feltstrom et al., 2004). Whether this dose-dependent effect of insulin on its secretion explains such controversial findings is elusive.

Now, if insulin indeed displays an inhibitory action on its own secretion in vivo, how can the increase in GSIS after insulin infusion be explained? (Halperin et al., 2012). From studies conducted by the same research group (Bouche et al., 2010; Lopez et al., 2011; Halperin et al., 2012), it is acknowledged that glucagon, cortisol, free-fatty acids or potassium are likely not responsible. We then propose that an endocrine factor signaling from skeletal muscle toward the pancreas may enhance insulin secretion. If insulin plays an inhibitory action on its secretion in vivo, this endocrine factor must be potent enough to overcome that inhibition. We speculate that the release into circulation of 


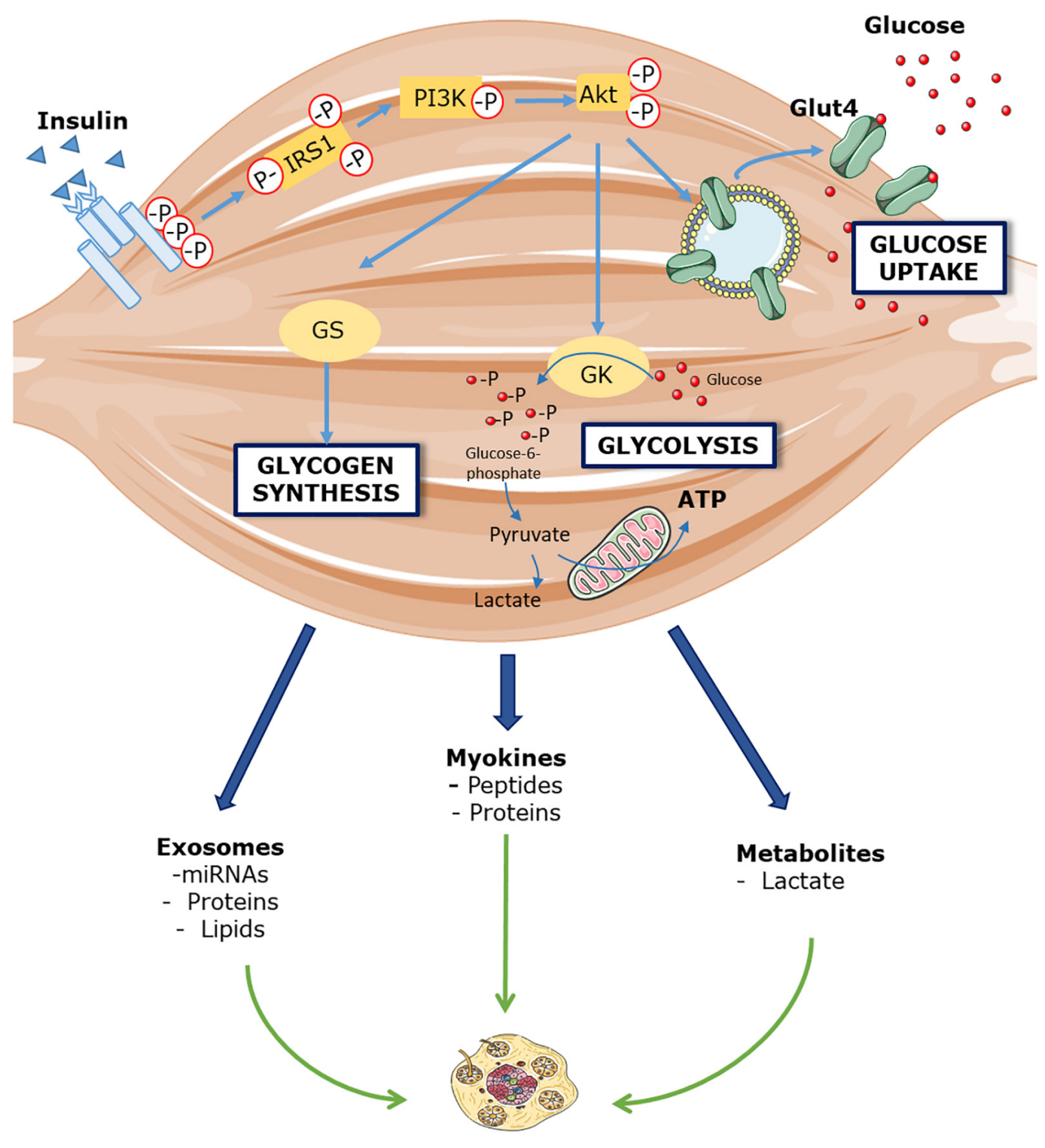

Islet of Langerhans

FIGURE 1 | Hypothetical model linking skeletal muscle insulin sensitivity and pancreatic insulin secretion. Insulin binds to its receptor located in skeletal muscle cells that triggers phosphorylation of Akt, a pivotal protein involved in insulin signaling. As a consequence, GLUT4 are translocated from cytosol to cell membrane, which increases facilitated transport of glucose into muscle cells. Increased cellular glucose flux will enhance its disposal by increasing glycogen synthesis and glucose utilization for ATP synthesis. Changes in glucose disposal at the level of uptake, storage or oxidation may be the signal to trigger the release of a putative factor into circulation, which can then influence insulin secretion directly through its action on beta cells, or indirectly through extra-pancreatic cell types.

that factor is triggered by insulin itself or the increase in glucose disposal (Figure 1).

Two mouse models with conditioned expression of specific proteins in skeletal muscle support this muscle-pancreas crosstalk. A loss-of-function of peroxisome proliferator-activated receptor $\gamma$ coactivator $1 \alpha(\mathrm{PGC} 1 \alpha)$ (Handschin et al., 2007) and a gain-of-function of muscle-specific RING-finger 1 protein (MuRF1) (Hirner et al., 2008) are accompanied by altered skeletal muscle glucose metabolism as well as abnormal insulin secretion in vivo. In the former study, the loss of PGC1 $\alpha$ expression at the muscle level induced glucose intolerance in mice due to hypoinsulinemia. Such defect in in vivo insulin secretion was not detected in isolated islets, suggesting that a circulating muscle-derived factor present in vivo plays a role. In this case, IL-6 was suggested as a candidate. The second study showed that overexpression of MuRF1 was accompanied of lower hepatic glycogen content and hyperinsulinemia. The authors concluded that an alteration of MuRF1 expression in skeletal muscle stimulates insulin secretion, providing a regulatory feedback loop between muscle 
and pancreas. Besides, we found that conditioned medium from human myotubes increases insulin secretion in isolated pancreatic islets (Bouzakri et al., 2011; Mizgier et al., 2017). Moreover, the contribution of skeletal muscle on GSIS seems to be fiber specific (Rutti et al., 2018), adding further complexity to the muscle-pancreas axis. These data suggest that insulin secretion is influenced through muscle-derived factors released in response to modifications in skeletal muscle glucose metabolism. A muscle-to-pancreas communication therefore seems to exist.

\section{MUSCLE-RELEASED FACTORS TARGETING INSULIN SECRETION}

\section{Myokines}

Myokines having influence on insulin secretion should express their receptors in pancreatic islets. Because dozens and even hundreds of proteins have been detected in conditioned media from human muscle cells (Hartwig et al., 2014; Weigert et al., 2014), we first compared the presence of selected proteins in different studies (see Supplementary Table 2 for further details). Nineteen out of 73 (26\%) proteins were consistently detected regardless of the detection method (Raschke et al., 2013; Scheler et al., 2013; Hartwig et al., 2014). Among secreted proteins, interleukins (IL) 1-beta, 2, $6,7,8,10$, and 12 stand out. Also, chemokines such as monocyte chemoattractant protein-1 (MCP1/CCL2); regulated on activation, normal $\mathrm{T}$ cell expressed and secreted (Rantes); and growth-regulated oncogene (GRO) alpha, beta and gamma. The proteins detected by at least two analytical approaches were selected for a gene expression search of their receptors in human, mouse and rat pancreatic islets and beta cells in the Beta Cell Gene Atlas (Smink et al., 2005; Table 1). Many of the selected proteins do express their receptors in islets or beta cells, which opens the number of potential endocrine candidates. Most of these proteins have often more than one receptor belonging to CC or CXC receptor families, which adds further complexity to the quest for endocrine muscle-pancreas mediators. As an example of the complexity, CXCL10 appears to interact with the toll-like receptor 4 but not with its known receptor (CXCR3) in beta cells (Schulthess et al., 2009). Additionally, myokine receptors may also be located in extra-pancreatic tissues. For instance, IL6 binds to receptors located in intestinal L cells to stimulate glucagon-like peptide 1 secretion, which then can enhance GSIS (Ellingsgaard et al., 2011).

The effect of specific myokines on beta cell function has been assessed by using their recombinant forms. IL- 6 showed a stimulatory action on GSIS in mice after an acute injection (400 ng) that emulated its circulating concentration in response to exercise or high-fat diet (Ellingsgaard et al., 2011). By contrast, neutral (Ellingsgaard et al., 2008) or inhibitory (Handschin et al., 2007) actions are also reported. These controversial outcomes might be due to different IL-6 levels achieved. Physiological concentrations of IL-6 ( $<100 \mathrm{pg} / \mathrm{mL})$ had antiinflammatory effect and show a stimulatory action on GSIS
(Andreozzi et al., 2006; Ellingsgaard et al., 2011). In turn, higher IL-6 concentrations (500-25000 pg/mL) show inhibitory action on GSIS (Sandler et al., 1990; Southern et al., 1990; Eizirik et al., 1994).

Additional cytokine assessment includes IL-12, CXCL10 and fractalkine (CX3CL1). Both IL-12 and CXCL10 have shown to impair GSIS in INS-1 cells (Taylor-Fishwick et al., 2013) and in human islets (Schulthess et al., 2009; Taylor-Fishwick et al., 2013). In turn, fractalkine at $100 \mathrm{ng} / \mathrm{mL}$ increased GSIS in human islets and in a mouse beta cell line (MIN6) (Lee et al., 2013). However, fractalkine did not influence GSIS when added at a lower concentration in sorted rat beta cells or human islets (Rutti et al., 2014), although it prevented tumor necrosis factor alphainduced GSIS reduction in sorted rat beta cells (Rutti et al., 2014). The type of receptor also plays a role in determining the action of its ligand. For instance, Rantes appears to have a stimulatory effect when bound to GPR75 receptor (Liu et al., 2013), while an inhibitory action when bound to CCR1 receptor (Pais et al., 2014).

An additional aspect to take into account when searching for potential endocrine mediators is to distinguish among proteins released from cell lysis vs. an active, regulated secretion process. In fact, many detected proteins do not seem to be secreted as they have no signal peptide, known receptor and their described function is at the intracellular level (Supplementary Table 3). Thus, the myokinome may include a much lower number of proteins than previously anticipated.

\section{Exosomes and Their Cargo}

Extracellular vesicles are a heterogeneous population of cellderived membranous structures including microvesicles and exosomes. Exosomes are the smallest vesicles (ranging from 30 to $100 \mathrm{~nm}$ of diameter) formed by the fusion of multivesicular endosomes with the plasma membrane (van Niel et al., 2018). Exosomes carry proteins, lipids and nucleic acids [e.g., micro (mi)RNAs] (van Niel et al., 2018). Released exosomes can dock to the plasma membrane of a target cell, where they can fuse with the plasma membrane or be endocytosed before delivering its cargo (Raposo and Stoorvogel, 2013). Some evidence suggests a role in cell-to-cell and organ-to-organ communication, particularly through miRNAs (Camussi et al., 2010). However, the role of exosomes in whole-body homeostasis remains unclear.

Skeletal muscle cells can release exosomes (Forterre et al., 2014) and miRNAs (contained or not in exosomes) (Aoi and Sakuma, 2014). Furthermore, exercise and metabolic diseases such as type 2 diabetes (T2D) affect the expression of several muscle-derived miRNAs (myomiRs). For instance, miR-1 and miR-133a expressions are increased by acute endurance exercise in untrained subjects while miR-133b and miR-206 are not affected by acute exercise (Nielsen et al., 2010). In turn, all of these myomiRs were downregulated after a 12 week training period (Nielsen et al., 2010). Other myomiRs such as miR-23b/27b are down-regulated during muscle cell differentiation in individuals with T2D vs. healthy subjects (Henriksen et al., 2017), while the miR-29 family is up-regulated in muscle from T2D vs. nondiabetic donors (Massart et al., 2017). 
TABLE 1 | Receptor expression in human, mouse and rat pancreatic islets and beta cells of cytokines and chemokines detected in conditioned media from human myotubes.

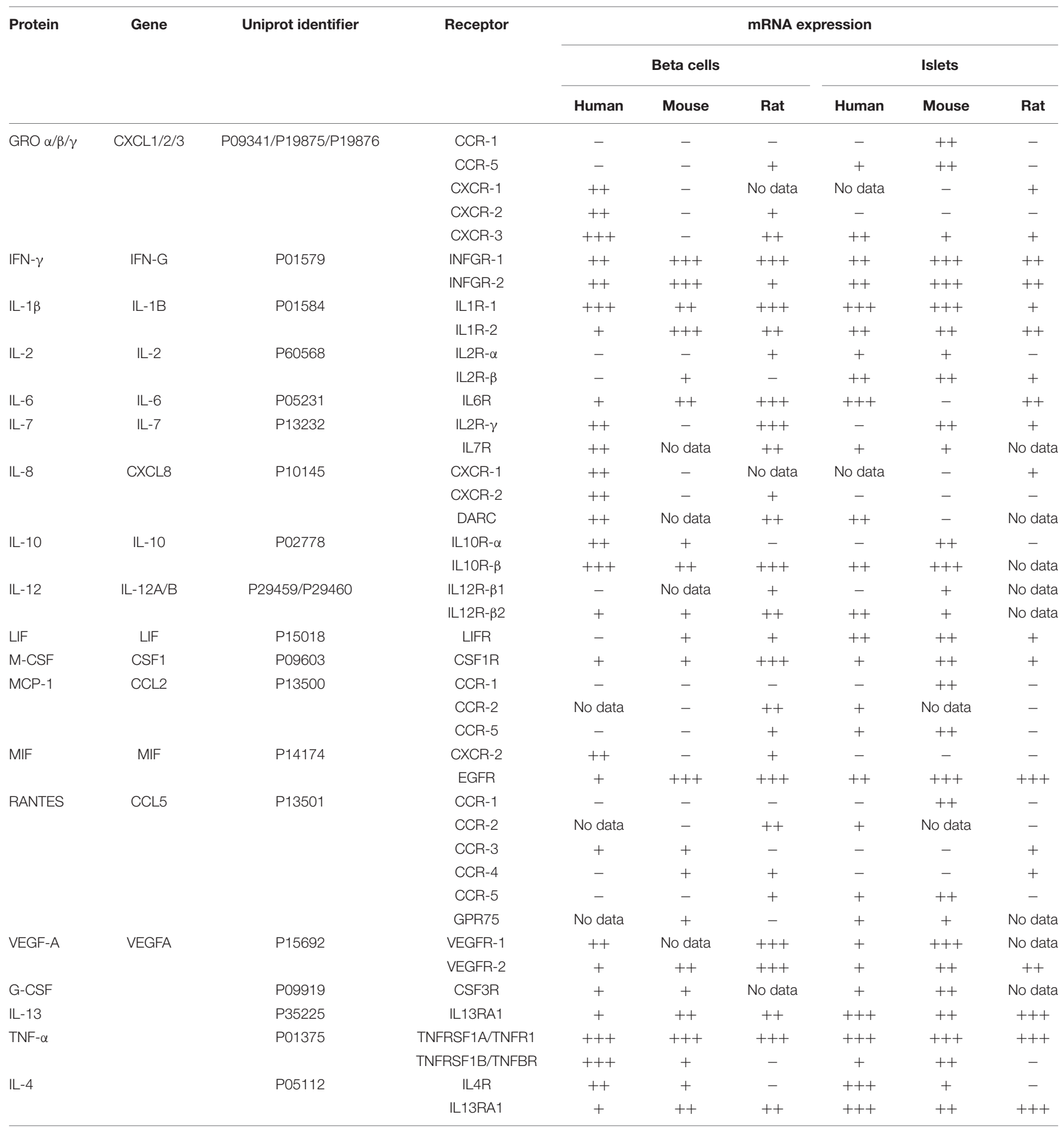

Specific receptor name for each cytokine and chemokine detected in human myotube conditioned media in Hartwig et al. (2014) and Mizgier et al. (2017) studies (see Supplementary Table 2) were identified browsing the UniProt and STRING protein databases. Receptor mRNA expression were obtained from the Beta Cell Gene Atlas (Smink et al., 2005). Low (+), moderate (++), enriched (+++) expression level; not expressed (-).

Besides myomiRs expression being affected by exercise or diabetic status, exosome-associated miRNAs can also be transferred to other cell types. In this regard, Jalabert et al. (2016) found that skeletal muscle-derived exosomes injected into mice specifically targeted pancreatic islet cells and affected gene expression and proliferation of beta cells. Whether or not skeletal muscle-derived exosomes can influence insulin secretion deserves attention. 


\section{Metabolites}

The interaction between muscle and pancreas may not be restricted to myokines and exosomes. Metabolites such as lactate may also participate, considering that skeletal muscle plays a predominant role in lactate metabolism. In addition, we (Galgani et al., 2013) and others (Lovejoy et al., 1992) have found a direct correlation between plasma lactate concentration and insulin resistance. Thus, lactate might represent a candidate for linking skeletal muscle insulin sensitivity with insulin secretion. However, its actual relevance in driving insulin secretion is controversial. On the one hand, lactate showed to stimulate in vitro insulin secretion (Meats et al., 1989; Akiyoshi et al., 1999). On the other hand, lactate was reported to have a null effect on insulin secretion (Ishihara et al., 1999). The latter explained by lacking expression of the monocarboxylate transporter 1 in pancreatic beta cells (Ishihara et al., 1999; Schuit et al., 2012).

\section{CONCLUSION}

For many years, the inverse relationship between insulin sensitivity and its secretion is known. However, an underlying mechanism relating these processes remains elusive. Strikingly, in vivo animal (Handschin et al., 2007; Hirner et al., 2008) and human (Mari et al., 2011; Halperin et al., 2012) studies show that changes in skeletal muscle glucose metabolism are accompanied by differential insulin secretion. Some of the evidence has been mostly interpreted as a direct role of insulin on its own secretion (Mari et al., 2011; Halperin et al., 2012). Because insulin drastically increases skeletal muscle glucose metabolism, we propose that a putative interaction between skeletal muscle and the pancreas may proceed. Assessing a causal relationship between these processes is challenging. It requires altering muscle glucose metabolism while maintaining similar blood glucose and insulin concentration. Under that setting, it will be essential to combine blood sampling from arterio-venous balance with proteomic analysis. Such assessment will contribute to identifying such an endocrine factor (or refute its existence) in conditions of physiological (e.g., transition from fasting to postprandial) and pathophysiological (e.g., normal vs. abnormal glycemic control) relevance.

The definition of myokine also needs to be revisited. At present, many muscle cell-derived proteins are named myokines. However, there is no evidence that those factors can indeed affect the function of any organ in vivo. Perhaps, the strongest evidence

\section{REFERENCES}

Akiyoshi, H., Iwamoto, M., and Nakaya, Y. (1999). Lactate stimulates insulin secretion without blocking the $\mathrm{K}+$ channels in HIT-T15 insulinoma cells. Horm. Metab. Res. 31, 257-261. doi: 10.1055/s-2007-97 8728

Andreozzi, F., Laratta, E., Cardellini, M., Marini, M. A., Lauro, R., Hribal, M. L., et al. (2006). Plasma interleukin-6 levels are independently associated with insulin secretion in a cohort of Italian-Caucasian nondiabetic subjects. Diabetes 55, 2021-2024. doi: 10.2337/db06-0063

Aoi, W., and Sakuma, K. (2014). Does regulation of skeletal muscle function involve circulating microRNAs? Front. Physiol. 5:39. doi: 10.3389/fphys.2014. 00039 for supporting an endocrine role of a myokine on a distant organ is attributed to IL-6. Thus, in individuals undergoing a 12 week exercise training, blocking IL-6 action (by infusing an IL6 receptor antibody) prevented the decrease in visceral fat mass as detected in participants receiving vehicle infusion (WedellNeergaard et al., 2018). Authors interpreted that finding as proof of the lipolytic action of IL-6 shown in earlier studies (van Hall et al., 2003). Certainly, Wedell-Neergaard's study cannot claim that muscle-derived IL-6 was responsible of decreasing visceral fat mass. In any case, it is the strongest current evidence in humans linking skeletal muscle contraction with changes in a distant tissue throughout a circulating factor. Whether or not blocking IL-6 action had any effect on insulin secretion after exercise training deserves analysis.

Finally, one should bear in mind that besides skeletal muscle, organs such as the liver and adipose tissue, may also secrete a number of factors into circulation. Those factors may play a role in mediating the interaction between insulin sensitivity and its secretion. Identifying the mechanism linking insulin sensitivity with insulin secretion, in particular in dynamic states such as the transition from fasting to postprandial conditions, may have a strong impact on designing therapies for improving insulin secretion in pre-diabetic and diabetic individuals.

\section{AUTHOR CONTRIBUTIONS}

MM and JG conceived the present idea and drafted the manuscript. All authors revised and approved the final version of the manuscript.

\section{FUNDING}

This project has received funding from the European Union's Horizon 2020 Research and Innovation Programme under the Marie Skłodowska-Curie Action grant agreement 753670 (to MM) and from FONDECYT 1130217 and 1170117 (to JG).

\section{SUPPLEMENTARY MATERIAL}

The Supplementary Material for this article can be found online at: https://www.frontiersin.org/articles/10.3389/fphys. 2019.01024/full\#supplementary-material

Araujo, E. P., Amaral, M. E., Souza, C. T., Bordin, S., Ferreira, F., Saad, M. J., et al. (2002). Blockade of IRS1 in isolated rat pancreatic islets improves glucoseinduced insulin secretion. FEBS Lett. 531, 437-442. doi: 10.1016/s00145793(02)03580-9

Aspinwall, C. A., Lakey, J. R., and Kennedy, R. T. (1999). Insulin-stimulated insulin secretion in single pancreatic beta cells. J. Biol. Chem. 274, 6360-6365. doi: $10.1074 /$ jbc. 274.10 .6360

Baron, A. D., Brechtel, G., Wallace, P., and Edelman, S. V. (1988). Rates and tissue sites of non-insulin- and insulin-mediated glucose uptake in humans. Am. J. Physiol. Endocrinol. Metab. 255, E769-E774. doi: 10.1152/ajpendo.1988.255. 6.E769

Bouche, C., Lopez, X., Fleischman, A., Cypess, A. M., O’Shea, S., Stefanovski, D., et al. (2010). Insulin enhances glucose-stimulated insulin secretion in 
healthy humans. Proc. Natl. Acad. Sci. U.S.A. 107, 4770-4775. doi: 10.1073/pnas. 1000002107

Bouzakri, K., Plomgaard, P., Berney, T., Donath, M. Y., Pedersen, B. K., and Halban, P. A. (2011). Bimodal effect on pancreatic $\beta$-cells of secretory products from normal or insulin-resistant human skeletal muscle. Diabetes 60, 11111121. doi: $10.2337 / \mathrm{db} 10-1178$

Camussi, G., Deregibus, M. C., Bruno, S., Cantaluppi, V., and Biancone, L. (2010). Exosomes/microvesicles as a mechanism of cell-to-cell communication. Kidney Int. 78, 838-848. doi: 10.1038/ki.2010.278

Caporarello, N., Parrino, C., Trischitta, V., and Frittitta, L. (2017). Insulin receptor signaling and glucagon-like peptide 1 effects on pancreatic beta cells. PLoS One 12:e0181190. doi: 10.1371/journal.pone.0181190

Collier, J. J., White, S. M., Dick, G. M., and Scott, D. K. (2004). Phosphatidylinositol 3-kinase inhibitors reveal a unique mechanism of enhancing insulin secretion in 832/13 rat insulinoma cells. Biochem. Biophys. Res. Commun. 324, 1018-1023. doi: 10.1016/j.bbrc.2004.09.149

Daskalaki, E., Pillon, N. J., Krook, A., Wheelock, C. E., and Checa, A. (2018). The influence of culture media upon observed cell secretome metabolite profiles: the balance between cell viability and data interpretability. Anal. Chim. Acta 1037, 338-350. doi: 10.1016/j.aca.2018.04.034

Eizirik, D. L., Sandler, S., Welsh, N., Cetkovic-Cvrlje, M., Nieman, A., Geller, D. A., et al. (1994). Cytokines suppress human islet function irrespective of their effects on nitric oxide generation. J. Clin. Invest. 93, 1968-1974. doi: 10.1172/JCI117188

Ellingsgaard, H., Ehses, J. A., Hammar, E. B., Van Lommel, L., Quintens, R., Martens, G., et al. (2008). Interleukin-6 regulates pancreatic $\alpha$-cell mass expansion. Proc. Natl. Acad. Sci. U.S.A. 105, 13163-13168. doi: 10.1073/pnas. 0801059105

Ellingsgaard, H., Hauselmann, I., Schuler, B., Habib, A. M., Baggio, L. L., Meier, D. T., et al. (2011). Interleukin-6 enhances insulin secretion by increasing glucagon-like peptide-1 secretion from L cells and alpha cells. Nat. Med. 17, 1481-1489. doi: $10.1038 / \mathrm{nm} .2513$

Forterre, A., Jalabert, A., Berger, E., Baudet, M., Chikh, K., Errazuriz, E., et al. (2014). Proteomic analysis of $\mathrm{C} 2 \mathrm{C} 12$ myoblast and myotube exosome-like vesicles: a new paradigm for myoblast-myotube cross talk? PLoS One 9:e84153. doi: 10.1371 /journal.pone. 0084153

Galgani, J. E., Mizgier, M. L., Mari, A., and Ravussin, E. (2014). Relationship between whole-body macronutrient oxidative partitioning and pancreatic insulin secretion/beta-cell function in non-diabetic humans. Metabolism 63, 1426-1431. doi: 10.1016/j.metabol.2014.08.002

Galgani, J. E., and Ravussin, E. (2012). Postprandial whole-body glycolysis is similar in insulin-resistant and insulin-sensitive non-diabetic humans. Diabetologia 55, 737-742. doi: 10.1007/s00125-011-241-0

Galgani, J. E., Vasquez, K., Watkins, G., Dupuy, A., Bertrand-Michel, J., Levade, T., et al. (2013). Enhanced skeletal muscle lipid oxidative efficiency in insulinresistant vs insulin-sensitive nondiabetic, nonobese humans. J. Clin. Endocrinol. Metab. 98, E646-E653. doi: 10.1210/jc.2012-3111

Halperin, F., Lopez, X., Manning, R., Kahn, C. R., Kulkarni, R. N., and Goldfine, A. B. (2012). Insulin augmentation of glucose-stimulated insulin secretion is impaired in insulin-resistant humans. Diabetes 61, 301-309. doi: 10.2337/db111067

Handschin, C., Choi, C. S., Chin, S., Kim, S., Kawamori, D., Kurpad, A. J., et al. (2007). Abnormal glucose homeostasis in skeletal muscle-specific PGC-1alpha knockout mice reveals skeletal muscle-pancreatic beta cell crosstalk. J. Clin. Invest. 117, 3463-3474. doi: 10.1172/JCI31785

Hartwig, S., Raschke, S., Knebel, B., Scheler, M., Irmler, M., Passlack, W., et al. (2014). Secretome profiling of primary human skeletal muscle cells. Biochim. Biophys. Acta 1844, 1011-1017. doi: 10.1016/j.bbapap.2013. 08.004

Henriksen, T. I., Davidsen, P. K., Pedersen, M., Schultz, H. S., Hansen, N. S., Larsen, T. J., et al. (2017). Dysregulation of a novel miR-23b/27b-p53 axis impairs muscle stem cell differentiation of humans with type 2 diabetes. Mol. Metab. 6, 770-779. doi: 10.1016/j.molmet.2017.04.006

Hirner, S., Krohne, C., Schuster, A., Hoffmann, S., Witt, S., Erber, R., et al. (2008). MuRF1-dependent regulation of systemic carbohydrate metabolism as revealed from transgenic mouse studies. J. Mol. Biol. 379, 666-677. doi: 10.1016/j.jmb. 2008.03.049
Ishihara, H., Wang, H., Drewes, L. R., and Wollheim, C. B. (1999). Overexpression of monocarboxylate transporter and lactate dehydrogenase alters insulin secretory responses to pyruvate and lactate in beta cells. J. Clin. Invest. 104, 1621-1629. doi: 10.1172/JCI7515

Iversen, J., and Miles, D. W. (1971). Evidence for a feedback inhibition of insulin on insulin secretion in the isolated, perfused canine pancreas. Diabetes 20, 1-9. doi: $10.2337 /$ diab.20.1.1

Jalabert, A., Vial, G., Guay, C., Wiklander, O. P., Nordin, J. Z., Aswad, H., et al. (2016). Exosome-like vesicles released from lipid-induced insulin-resistant muscles modulate gene expression and proliferation of beta recipient cells in mice. Diabetologia 59, 1049-1058. doi: 10.1007/s00125-016-3882-y

Jimenez-Feltstrom, J., Lundquist, I., Obermuller, S., and Salehi, A. (2004). Insulin feedback actions: complex effects involving isoforms of islet nitric oxide synthase. Regul. Pept. 122, 109-118. doi: 10.1016/j.regpep.2004.06.004

Johnson, J. D., and Misler, S. (2002). Nicotinic acid-adenine dinucleotide phosphate-sensitive calcium stores initiate insulin signaling in human beta cells. Proc. Natl. Acad. Sci. U.S.A. 99, 14566-14571. doi: 10.1073/pnas.222099799

Kahn, S. E., Beard, J. C., Schwartz, M. W., Ward, W. K., Ding, H. L., Bergman, R. N., et al. (1989). Increased beta-cell secretory capacity as mechanism for islet adaptation to nicotinic acid-induced insulin resistance. Diabetes 38, 562-568. doi: $10.2337 /$ diabetes.38.5.562

Kahn, S. E., Larson, V. G., Beard, J. C., Cain, K. C., Fellingham, G. W., Schwartz, R. S., et al. (1990). Effect of exercise on insulin action, glucose tolerance, and insulin secretion in aging. Am. J. Physiol. 258(6 Pt 1), E937-E943. doi: 10.1152/ ajpendo.1990.258.6.E937

Lee, Y. S., Morinaga, H., Kim, J. J., Lagakos, W., Taylor, S., Keshwani, M., et al. (2013). The fractalkine/CX3CR1 system regulates $\beta$ cell function and insulin secretion. Cell 153, 413-425. doi: 10.1016/j.cell.2013.03.001

Leibiger, I. B., Leibiger, B., and Berggren, P. O. (2008). Insulin signaling in the pancreatic beta-cell. Annu. Rev. Nutr. 28, 233-251. doi: 10.1146/annurev.nutr. 28.061807.155530

Liu, B., Hassan, Z., Amisten, S., King, A. J., Bowe, J. E., Huang, G. C., et al. (2013). The novel chemokine receptor, G-protein-coupled receptor 75 , is expressed by islets and is coupled to stimulation of insulin secretion and improved glucose homeostasis. Diabetologia 56, 2467-2476. doi: 10.1007/s00125-013-3022-x

Lopez, X., Cypess, A., Manning, R., O’Shea, S., Kulkarni, R. N., and Goldfine, A. B. (2011). Exogenous insulin enhances glucose-stimulated insulin response in healthy humans independent of changes in free fatty acids. J. Clin. Endocrinol. Metab. 96, 3811-3821. doi: 10.1210/jc.2011-0627

Lovejoy, J., Newby, F. D., Gebhart, S. S., and DiGirolamo, M. (1992). Insulin resistance in obesity is associated with elevated basal lactate levels and diminished lactate appearance following intravenous glucose and insulin. Metabolism 41, 22-27. doi: 10.1016/0026-0495(92)90185-d

Mari, A., Tura, A., Natali, A., Anderwald, C., Balkau, B., Lalic, N., et al. (2011). Influence of hyperinsulinemia and insulin resistance on in vivo beta-cell function: their role in human beta-cell dysfunction. Diabetes 60, 3141-3147. doi: $10.2337 / \mathrm{db} 11-0827$

Massart, J., Sjogren, R. J. O., Lundell, L. S., Mudry, J. M., Franck, N., O'Gorman, D. J., et al. (2017). Altered miR-29 expression in type 2 diabetes influences glucose and lipid metabolism in skeletal muscle. Diabetes 66, 1807-1818. doi: $10.2337 / \mathrm{db} 17-0141$

Meats, J. E., Tuersley, M. D., Best, L., Lynch, A. M., and Tomlinson, S. (1989). Lactate alters plasma membrane potential, increases the concentration of cytosolic $\mathrm{Ca} 2+$ and stimulates the secretion of insulin by the hamster beta-cell line HIT-T15. J. Mol. Endocrinol. 3, 121-128. doi: 10.1677/jme.0.0030121

Mizgier, M. L., Casas, M., Contreras-Ferrat, A., Llanos, P., and Galgani, J. E. (2014). Potential role of skeletal muscle glucose metabolism on the regulation of insulin secretion. Obes. Rev. 15, 587-597. doi: 10.1111/obr.12166

Mizgier, M. L., Cataldo, L. R., Gutierrez, J., Santos, J. L., Casas, M., Llanos, P., et al. (2017). Effect of human myotubes-derived media on glucose-stimulated insulin secretion. J. Diabetes Res. 2017:1328573. doi: 10.1155/2017/1328573

Nielsen, S., Scheele, C., Yfanti, C., Akerstrom, T., Nielsen, A. R., Pedersen, B. K., et al. (2010). Muscle specific microRNAs are regulated by endurance exercise in human skeletal muscle. J. Physiol. 588(Pt 20), 4029-4037. doi: 10.1113/jphysiol. 2010.189860

Pais, R., Zietek, T., Hauner, H., Daniel, H., and Skurk, T. (2014). RANTES (CCL5) reduces glucose-dependent secretion of glucagon-like peptides 1 and 2 and 
impairs glucose-induced insulin secretion in mice. Am. J. Physiol. Gastrointest. Liver Physiol. 307, G330-G337. doi: 10.1152/ajpgi.00329.2013

Persaud, S. J., Asare-Anane, H., and Jones, P. M. (2002). Insulin receptor activation inhibits insulin secretion from human islets of langerhans. FEBS Lett. 510, 225-228. doi: 10.1016/s0014-5793(01)03268-9

Petersen, K. F., Dufour, S., Befroy, D., Garcia, R., and Shulman, G. I. (2004). Impaired mitochondrial activity in the insulin-resistant offspring of patients with type 2 diabetes. N. Engl. J. Med. 350, 664-671. doi: 10.1056/ NEJMoa031314

Pillon, N. J., Bilan, P. J., Fink, L. N., and Klip, A. (2013). Cross-talk between skeletal muscle and immune cells: muscle-derived mediators and metabolic implications. Am. J. Physiol. Endocrinol. Metab. 304, E453-E465. doi: 10.1152/ ajpendo.00553.2012

Porte, D. (1969). Sympathetic regulation of insulin secretion. Its relation to diabetes mellitus. Arch. Intern. Med. 123, 252-260. doi: 10.1001/archinte.123. 3.252

Raposo, G., and Stoorvogel, W. (2013). Extracellular vesicles: exosomes, microvesicles, and friends. J. Cell Biol. 200, 373-383. doi: 10.1083/jcb. 201211138

Raschke, S., Eckardt, K., Bjorklund Holven, K., Jensen, J., and Eckel, J. (2013). Identification and validation of novel contraction-regulated myokines released from primary human skeletal muscle cells. PLoS One 8:e62008. doi: 10.1371/ journal.pone.0062008

Rorsman, P., and Braun, M. (2013). Regulation of insulin secretion in human pancreatic islets. Annu. Rev. Physiol. 75, 155-179. doi: 10.1146/annurevphysiol-030212-183754

Rutti, S., Arous, C., Schvartz, D., Timper, K., Sanchez, J. C., Dermitzakis, E., et al. (2014). Fractalkine (CX3CL1), a new factor protecting beta-cells against TNFalpha. Mol. Metab. 3, 731-741. doi: 10.1016/j.molmet.2014.07.007

Rutti, S., Dusaulcy, R., Hansen, J. S., Howald, C., Dermitzakis, E. T., Pedersen, B. K., et al. (2018). Angiogenin and osteoprotegerin are type II muscle specific myokines protecting pancreatic beta-cells against proinflammatory cytokines. Sci. Rep. 8:10072. doi: 10.1038/s41598-018-28117-2

Sandler, S., Bendtzen, K., Eizirik, D. L., and Welsh, M. (1990). Interleukin-6 affects insulin secretion and glucose metabolism of rat pancreatic islets in vitro. Endocrinology 126, 1288-1294. doi: 10.1210/endo-126-2-1288

Scheler, M., Irmler, M., Lehr, S., Hartwig, S., Staiger, H., Al-Hasani, H., et al. (2013). Cytokine response of primary human myotubes in an in vitro exercise model. Am. J. Physiol. Cell Physiol. 305, C877-C886. doi: 10.1152/ajpcell.00043.2013

Schuit, F., Van Lommel, L., Granvik, M., Goyvaerts, L., de Faudeur, G., Schraenen, A., et al. (2012). beta-cell-specific gene repression: a mechanism to protect against inappropriate or maladjusted insulin secretion? Diabetes 61, 969-975. doi: $10.2337 / \mathrm{db} 11-1564$
Schulthess, F. T., Paroni, F., Sauter, N. S., Shu, L., Ribaux, P., Haataja, L., et al. (2009). CXCL10 impairs beta cell function and viability in diabetes through TLR4 signaling. Cell Metab. 9, 125-139. doi: 10.1016/j.cmet.2009.01.003

Smink, L. J., Helton, E. M., Healy, B. C., Cavnor, C. C., Lam, A. C., Flamez, D., et al. (2005). T1DBase, a community web-based resource for type 1 diabetes research. Nucleic Acids Res. 33, D544-D549. doi: 10.1093/nar/gki095

Southern, C., Schulster, D., and Green, I. C. (1990). Inhibition of insulin secretion from rat islets of langerhans by interleukin-6. An effect distinct from that of interleukin-1. Biochem. J. 272, 243-245. doi: 10.1042/bj2720243

Srivastava, S., and Goren, H. J. (2003). Insulin constitutively secreted by beta-cells is necessary for glucose-stimulated insulin secretion. Diabetes 52, 2049-2056. doi: $10.2337 /$ diabetes.52.8.2049

Taylor-Fishwick, D. A., Weaver, J. R., Grzesik, W., Chakrabarti, S., Green-Mitchell, S., Imai, Y., et al. (2013). Production and function of IL-12 in islets and beta cells. Diabetologia 56, 126-135. doi: 10.1007/s00125-012-2732-9

van Hall, G., Steensberg, A., Sacchetti, M., Fischer, C., Keller, C., Schjerling, P., et al. (2003). Interleukin-6 stimulates lipolysis and fat oxidation in humans. J. Clin. Endocrinol. Metab. 88, 3005-3010. doi: 10.1210/jc.2002-021687

van Niel, G., D’Angelo, G., and Raposo, G. (2018). Shedding light on the cell biology of extracellular vesicles. Nat. Rev. Mol. Cell Biol. 19, 213-228. doi: 10.1038/nrm.2017.125

Wedell-Neergaard, A. S., Lang Lehrskov, L., Christensen, R. H., Legaard, G. E., Dorph, E., Larsen, M. K., et al. (2018). Exercise-induced changes in visceral adipose tissue mass are regulated by IL- 6 signaling: a randomized controlled trial. Cell Metab. 29, 844-855. doi: 10.1016/j.cmet.2018.12.007

Weigert, C., Lehmann, R., Hartwig, S., and Lehr, S. (2014). The secretome of the working human skeletal muscle-a promising opportunity to combat the metabolic disaster? Proteomics Clin. Appl. 8, 5-18. doi: 10.1002/prca.201300094

Zawalich, W. S., and Zawalich, K. C. (2002). Effects of glucose, exogenous insulin, and carbachol on C-peptide and insulin secretion from isolated perifused rat islets. J. Biol. Chem. 277, 26233-26237. doi: 10.1074/jbc.M202291200

Conflict of Interest Statement: The authors declare that the research was conducted in the absence of any commercial or financial relationships that could be construed as a potential conflict of interest.

Copyright (c) 2019 Mizgier, Fernández-Verdejo, Cherfan, Pinget, Bouzakri and Galgani. This is an open-access article distributed under the terms of the Creative Commons Attribution License (CC BY). The use, distribution or reproduction in other forums is permitted, provided the original author(s) and the copyright owner(s) are credited and that the original publication in this journal is cited, in accordance with accepted academic practice. No use, distribution or reproduction is permitted which does not comply with these terms. 